\title{
Aspirin for primary prevention of coronary heart disease: safety and absolute benefit related to coronary risk derived from meta-analysis of randomised trials
}

\author{
P S Sanmuganathan, P Ghahramani, P R Jackson, E J Wallis, L E Ramsay
}

\begin{abstract}
Objective-To determine the cardiovascular and coronary risk thresholds at which aspirin for primary prevention of coronary heart disease is safe and worthwhile.

Design-Meta-analysis of four randomised controlled trials of aspirin for primary prevention. The benefit and harm from aspirin treatment were examined to determine: (1) the cardiovascular and coronary risk threshold at which benefit in prevention of myocardial infarction exceeds harm from significant bleeding; and (2) the absolute benefit expressed as number needed to treat (NNT) for aspirin net of cerebral haemorrhage and other bleeding complications at different levels of coronary risk.

Main outcome measures-Benefit from aspirin, expressed as reduction in cardiovascular events, myocardial infarctions, strokes, and total mortality; harm caused by aspirin in relation to significant bleeds and major haemorrhages.

Results-Aspirin for primary prevention significantly reduced all cardiovascular events by $15 \%$ (95\% confidence interval (CI) $6 \%$ to $22 \%$ ) and myocardial infarctions by $30 \%(95 \%$ CI $21 \%$ to $38 \%)$, and non-significantly reduced all deaths by $6 \%(95 \%$ CI $-4 \%$ to $15 \%)$. Aspirin non-significantly increased strokes by $6 \%(95 \%$ CI $-24 \%$ to $9 \%)$ and significantly increased bleeding complications by $69 \%$ ( $95 \%$ CI $38 \%$ to $107 \%$ ). The risk of major bleeding balanced the reduction in cardiovascular events when cardiovascular event risk was $0.22 \%$ /year. The upper $95 \%$ CI for this estimate suggests that harm from aspirin is unlikely to outweigh benefit provided the cardiovascular event risk is $0.8 \%$ /year, equivalent to a coronary risk of $0.6 \%$ /year. At coronary event risk $1.5 \%$ year, the five year NNT was 44 to prevent a myocardial infarction, and 77 to prevent a myocardial infarction net of any important bleeding complication. At coronary event risk $1 \%$ /year the NNT was 67 to prevent a myocardial infarction, and 182 to prevent a myocardial infarction net of important bleeding.

Conclusions-Aspirin treatment for primary prevention is safe and worthwhile at coronary event risk $\geqslant 1.5 \%$ /year; safe but of limited value at coronary risk $1 \% /$ year; and unsafe at coronary event risk $0.5 \% / y e a r$. Advice on aspirin for primary prevention requires formal accurate estimation of absolute coronary event risk.

(Heart 2001;85:265-271)
\end{abstract}

Keywords: aspirin; coronary heart disease; primary prevention; meta-analysis

Aspirin reduces the risk of non-fatal myocardial infarction by $34 \%,{ }^{1}$ and in the setting of secondary prevention reduces non-fatal strokes by $31 \%$, cardiovascular events by $27 \%$, and cardiovascular deaths by $18 \% .^{1}$ The relative risk reduction by aspirin appears constant, ${ }^{1-3}$ and absolute benefit is therefore determined by absolute coronary heart disease or cardiovascular risk. ${ }^{3}$ Aspirin causes cerebral ${ }^{2}$ and other haemorrhages, ${ }^{4-6}$ and this risk seems constant and independent of coronary heart disease risk. ${ }^{2}{ }^{3}$ The balance between benefit and harm is therefore related to absolute coronary heart disease risk. ${ }^{3}$ When used for secondary prevention, the benefit from aspirin readily outweighs possible harm from major haemorrhage, ${ }^{13} 7$ but in primary prevention the balance between benefit and harm is not clear cut. ${ }^{137}$ Benefit will probably exceed harm in those at high risk, ${ }^{37}$ but a safe threshold of coronary heart disease risk for primary prevention with aspirin has not been defined. ${ }^{1}$ The question is important, because aspirin certainly can pre- vent non-fatal myocardial infarction when used for primary prevention. ${ }^{4-6}$ Furthermore, $6-9 \%$ of healthy people take aspirin regularly. ${ }^{89}$ The aims of this analysis were to define the threshold of absolute coronary heart disease risk at which aspirin treatment is safe, and to quantitate benefit and harm from aspirin treatment at different levels of coronary heart disease risk.

\section{Methods}

TRIALS

Randomised controlled trials of aspirin for primary prevention were sought by Medline search from 1985 onwards, using the terms cardiovascular disease and aspirin, and by scrutiny of previous meta-analyses and review articles. Additional prespecified criteria were that the studies had to report total cardiovascular events, myocardial infarction, stroke, bleeding complications, and all cause mortality as primary or secondary end points. We found four studies, one of unifactorial design ${ }^{10}$ and three of multifactorial design. ${ }^{4-6}$ In one factorial 
study, aspirin was used alone or with warfarin, ${ }^{5}$ and only the results for aspirin alone were included to avoid possible interaction between treatments. From the trial reports we obtained the number of subjects, person-years of follow up, and rates for end points. Specific steps were not taken to identify unpublished studies, but a rigorous search carried out for a meta-analysis published in 1994 failed to find any. ${ }^{1}$

END POINTS

Myocardial infarction included definite fatal and non-fatal myocardial infarction, but not possible myocardial infarction, silent infarction, or angina. Stroke included definite and probable cerebral infarction, cerebral haemorrhage, and stroke of uncertain cause, but not transient ischaemic attacks. Cardiovascular events included myocardial infarction and stroke (as defined above) plus cardiovascular deaths. In the UK doctors study, ${ }^{10}$ we excluded deaths classed as "other vascular and related causes" (rheumatic endocardial, hypertensive disease, pulmonary embolism, aortic aneurysm, and other vascular).

Bleeding complications were not classified or reported uniformly in the four trials. ${ }^{11}$ To calculate an overall odds ratio for bleeding complications we used the end point that provided the best estimate for each trial. These were: for the US physicians study, ${ }^{4}$ bleeds that required transfusion or operation or were fatal; for the UK doctors study, ${ }^{10}$ all fatal and non-fatal bleeds tabulated; and for the thrombosis prevention trial (TPT) 5 and the hypertension optimal treatment (HOT) trial, $^{6}$ all bleeds tabulated excluding minor bleeds. Note that cerebral haemorrhages were not included as bleeding complications but were classed as strokes, for the reason given below. These best estimates for each trial were used to calculate a combined odds ratio for the risk of bleeding complications with aspirin. A uniform measure of absolute risk of bleeding could not be derived using data from all four trials. Bleeding complications were therefore classed as major bleeds-defined as non-cerebral bleeds that caused death, transfusion, or operation - which were reported for two trials ${ }^{4}$; and all non-minor bleeds-defined as all non-cerebral bleeds not classed as minor - which were reported for two trials, ${ }^{56}$ both of which used aspirin at a dose of $75 \mathrm{mg}$ daily. For the second analysis described below, examining net benefit from aspirin, the absolute risk of cerebral haemorrhage was taken from a recent meta-analysis of primary and secondary prevention trials that had used reliable diagnostic methods. ${ }^{2}$ The excess risk of cerebral haemorrhage was $0.12 / 100$ persons over 37 months, or $0.039 \% /$ year. (This metaanalysis has been misinterpreted as showing a risk of cerebral haemorrhage of $0.12 \% /$ year, ${ }^{3}$ but our estimate is correct ( $\mathrm{J} \mathrm{He}$, personal communication).)

STATISTICAL ANALYSES

For each trial absolute benefit or harm was calculated by subtracting event rates in the aspirin group from those in the control group. Odds ratios and $95 \%$ confidence intervals (CI) were calculated by $\log$ transformation, and the $\chi^{2}$ test was used to assess heterogeneity between trials at $\mathrm{p}<0.1$. Treatment effects across trials were estimated with weighting to calculate combined odds ratios and $95 \% \mathrm{CI}$, using a fixed effects model. ${ }^{12}$ Combined rates and odds ratios were used for all four trials, with two exceptions. The rates for major bleeds and all for non-minor bleeds were the weighted means from only two trials each, as described above.

Two analyses were performed, the first to define the safety of aspirin for primary prevention, and the second to determine best estimates for benefit, net of bleeding complications, at different levels of coronary heart disease risk.

\section{Safety of aspirin}

In this analysis the measure of benefit was all cardiovascular events, which includes cerebral haemorrhages. The measure of harm was major bleeds, as defined above, which excludes cerebral haemorrhages. Cerebral haemorrhage was handled in this way because it was diagnosed incompletely in some trials. In this analysis cerebral haemorrhage caused by aspirin reduces benefit from treatment rather than increasing harm. The alternative analysis, to strip cerebral haemorrhages out from cardiovascular events and count them as major bleeds, is appropriate for trials that used reliable methods to distinguish between haemorrhagic and non-haemorrhagic strokes. ${ }^{2}$ The absolute benefit from aspirin (reduction of all cardiovascular events) and harm attributable to aspirin (excess of major bleeds) was examined, assuming that the model of Lubsen and Tijssen holds. ${ }^{13}$ The reduction of cardiovascular events by aspirin was calculated using the combined odds ratio for cardiovascular disease events and assuming a constant relative risk reduction and hence a linear proportionate relation between benefit and absolute cardiovascular disease risk. ${ }^{13}$ The risk of major bleeds with aspirin was assumed to be constant and independent of cardiovascular disease risk, ${ }^{23}$ and was calculated using the odds ratio for bleeding complications from all the trials and the absolute risk of major bleeds from two trials. ${ }^{45}$ The 95\% confidence regions for benefit and harm over the range of cardiovascular disease event risks were estimated by the equation described by Armitage and Berry. ${ }^{12}$ The $95 \%$ CI for the level of cardiovascular disease event risk at which benefit equals harm was calculated using a joint probability of 0.95 for harm and benefit. This joint probability is related to the intersections between $78 \%$ CI around estimates of benefit and harm. ${ }^{12}$

Net benefit from aspirin related to coronary heart disease event risk

In this analysis reduction in myocardial infarction was used as the main measure of benefit because this end point accounted for all the benefit (see Results). Assuming relative risk reduction to be constant (as above) and using the combined odds ratio for all trials, the absolute reduction in myocardial infarction and the number needed to treat (NNT) for five years to prevent one myocardial infarct were calculated 
Table 1 Baseline characteristics of study populations

\begin{tabular}{lllll}
\hline & $U S^{4}$ & $U K^{10}$ & TPT & HOT \\
\hline Number & 22071 & 5139 & 2540 & 18790 \\
Aspirin & 11037 & 3429 & 1268 & 9399 \\
Placebo & 11034 & 1710 & 1272 & 9391 \\
Aspirin dose (mg/day) & 162.5 & 500 & 75 & 75 \\
Trial duration (years) & 5.0 & 6.0 & 6.8 & 3.8 \\
Male (\%) & 100 & 100 & 100 & 53 \\
Mean age (years) & NA & NA & 57.5 & 61.5 \\
<60 years (\%) & 75 & 47 & NA & NA \\
Smokers (\%) & 11 & 13 & 41 & 16 \\
Hypertension (\%) & 9 & 10 & 26 & 100 \\
Diabetes mellitus (\%) & 2 & 2 & NA & 8 \\
\hline
\end{tabular}

NA, not available.

for coronary heart disease event risks of $0.5 \%$, $1.0 \%$, and $1.5 \%$ a year. The benefit and NNT for preventing myocardial infarction net of cerebral haemorrhage, of cerebral haemorrhage plus major bleed, and of cerebral haemorrhage plus all non-minor bleeds were calculated at these same coronary heart disease event risk levels. The risk of all bleeding complications was assumed constant, independent of coronary heart disease risk. Confidence intervals for estimates of NNT were calculated as described by Altman. ${ }^{14}$

Table 2 Absolute risk, benefit, odds ratios (OR), and 95\% confidence intervals (CI) for cardiovascular events, myocardial infarctions, strokes, and all cause mortality

\begin{tabular}{|c|c|c|c|c|}
\hline & $\begin{array}{l}\text { Absolute risk in control } \\
\text { group (\%/year) }\end{array}$ & $\begin{array}{l}\text { Absolute benefit from } \\
\text { aspirin (\%/year) }\end{array}$ & $O R$ & $95 \% C I$ \\
\hline \multicolumn{5}{|l|}{ Cardiovascular events } \\
\hline $\mathrm{US}^{4}$ & 0.67 & 0.11 & 0.82 & 0.71 to 0.96 \\
\hline $\mathrm{UK}^{10}$ & 1.34 & -0.04 & 1.02 & 0.82 to 1.27 \\
\hline $\mathrm{TPT}^{5}$ & 1.71 & 0.41 & 0.74 & 0.57 to 0.97 \\
\hline HOT $^{6}$ & 1.05 & 0.16 & 0.85 & 0.73 to 0.99 \\
\hline Weighted mean & 0.92 & 0.13 & 0.85 & 0.78 to 0.94 \\
\hline \multicolumn{5}{|c|}{ Myocardial infarction } \\
\hline $\mathrm{US}^{4}$ & 0.44 & 0.18 & 0.56 & 0.48 to 0.71 \\
\hline $\mathrm{UK}^{10}$ & 0.93 & 0.03 & 0.96 & 0.73 to 1.25 \\
\hline $\mathrm{TPT}^{5}$ & 1.33 & 0.31 & 0.76 & 0.57 to 1.03 \\
\hline $\mathrm{HOT}^{6}$ & 0.36 & 0.13 & 0.65 & 0.49 to 0.85 \\
\hline Weighted mean & 0.52 & 0.15 & 0.70 & 0.62 to 0.79 \\
\hline \multicolumn{5}{|l|}{ Strokes } \\
\hline $\mathrm{US}^{4}$ & 0.18 & -0.04 & 1.22 & 0.93 to 1.59 \\
\hline $\mathrm{UK}^{10}$ & 0.41 & -0.07 & 1.16 & 0.80 to 1.68 \\
\hline $\mathrm{TPT}^{5}$ & 0.32 & 0.10 & 0.69 & 0.38 to 1.26 \\
\hline $\mathrm{HOT}^{6}$ & 0.42 & 0.01 & 0.98 & 0.78 to 1.24 \\
\hline Weighted mean & 0.29 & -0.02 & 1.06 & 0.91 to 1.24 \\
\hline \multicolumn{5}{|l|}{ All cause mortality } \\
\hline $\mathrm{US}^{4}$ & 0.41 & 0.02 & 0.96 & 0.79 to 1.15 \\
\hline $\mathrm{UK}^{10}$ & 1.59 & 0.16 & 0.88 & 0.71 to 1.09 \\
\hline $\mathrm{TPT}^{5}$ & 1.31 & -0.05 & 1.03 & 0.78 to 1.36 \\
\hline $\mathrm{HOT}^{6}$ & 0.86 & 0.06 & 0.93 & 0.79 to 1.09 \\
\hline Weighted mean & 0.73 & 0.05 & 0.94 & 0.85 to 1.04 \\
\hline
\end{tabular}

Table 3 Absolute risk, harm, odds ratios (OR), and 95\% confidence intervals (CI) for best overall estimate of haemorrhage, major bleeds, bleeds requiring transfusion, and non-minor bleeds

\begin{tabular}{lllll}
\hline & $\begin{array}{l}\text { Absolute risk in } \\
\text { control group } \\
\text { (\%/year) }\end{array}$ & $\begin{array}{l}\text { Absolute harm } \\
\text { from aspirin } \\
\text { (\%/year) }\end{array}$ & OR & 95\% CI \\
\hline $\begin{array}{l}\text { Best overall estimate of haemorrhage } \\
\text { US }^{4}\end{array}$ & 0.05 & & & \\
UK $^{10}$ & 0.10 & 0.04 & 1.70 & 1.08 to 2.66 \\
TPT $^{5}$ & 0.46 & 0.01 & 1.05 & 0.49 to 2.21 \\
HOT $^{6}$ & 0.18 & 0.23 & 1.53 & 1.01 to 2.32 \\
Weighted mean & $\mathbf{0 . 1 3}$ & 0.16 & 1.90 & 1.42 to 2.54 \\
Major non-cerebral bleeds & 0.05 & $\mathbf{0 . 0 9}$ & $\mathbf{1 . 6 9}$ & $\mathbf{1 . 3 8}$ to 2.07 \\
US $^{4}$ & & & & \\
TPT $^{5}$ & 0.05 & 0.04 & 1.70 & 1.08 to 2.66 \\
Weighted mean & $\mathbf{0 . 0 5}$ & 0.05 & 1.96 & 0.63 to 6.09 \\
Non-minor bleeds & & $\mathbf{0 . 0 4}$ & $\mathbf{1 . 7 3}$ & $\mathbf{1 . 1 4}$ to 2.63 \\
TPT & 0.46 & 0.23 & & \\
HOT & & & 1.53 & 1.01 to 2.32 \\
Weighted mean & 0.18 & 0.16 & 1.96 & 1.42 to 2.54 \\
\hline
\end{tabular}

\section{Results}

TRIALS OF ASPIRIN FOR PRIMARY PREVENTION Four randomised controlled trials, the US physicians health study, ${ }^{4} \mathrm{UK}$ doctors study, ${ }^{10}$ thrombosis prevention trial, ${ }^{5}$ and the HOT study $^{6}$ included 48540 people, of whom 25133 were treated with aspirin. Characteristics of the trial populations are summarised in table 1. Points of note are difference in aspirin dosage, from 75 to $500 \mathrm{mg}$ daily; only one trial (HOT) included women; and all participants in HOT had hypertension which was well controlled. $^{6}$

BENEFIT FROM ASPIRIN

Table 2 shows analyses for myocardial infarction, stroke, all cardiovascular events, and all cause mortality. In control groups the coronary heart disease event risk varied from $0.36 \%$ /year (HOT) to $1.33 \% /$ year (thrombosis prevention trial), and cardiovascular event risk from $0.67 \% /$ year (US physicians) to $1.71 \%$ /year (thrombosis prevention trial). There was no heterogeneity in relative risk reduction between trials for all cardiovascular events, stroke, or all cause mortality. There was significant heterogeneity in relative risk reduction for myocardial infarction $(p=0.03)$, which was attributable to the results of the UK doctors study (table 2). The analysis was continued despite this (see Discussion). The odds ratios and confidence intervals showed significant reductions overall in all cardiovascular events (by $15 \%$ ) and in myocardial infarction (by $30 \%$ ), a non-significant reduction in all cause mortality (by 6\%), and a non-significant increase in stroke incidence (by 6\%).

\section{BLEEDING COMPLICATIONS}

Table 3 shows best estimates of risk of bleeding for all four trials. The absolute rate in control groups varied widely, from $0.05 \% /$ year to $0.46 \% /$ year, because of different definitions. The odds ratios varied from 1.05 to 1.90 , with no significant heterogeneity, and the overall odds ratio was 1.69 (95\% CI, 1.38 to 2.07 ). For major bleeds (two trials), ${ }^{45}$ the rates in control groups were identical (0.05\%/year) and the odds ratio for aspirin treatment was 1.73 (95\% CI 1.14 to 2.63$)$. For all non-minor bleeds (two trials), ${ }^{5}$ the rates in control groups differed greatly $(0.18 \%$ /year and $0.46 \%$ /year), and the odds ratio for aspirin was 1.77 (95\% CI 1.40 to 2.25 )

\section{SAFETY OF ASPIRIN}

Figure 1 shows the reduction in all cardiovascular events by aspirin, related to cardiovascular event risk, assuming a constant $15 \%$ relative risk reduction (table 2); the excess of major non-cerebral bleeds related to aspirin, assuming independence from cardiovascular risk; and the $95 \%$ confidence limits. By extrapolation, benefit equals harm at a cardiovascular event risk of $0.22 \% /$ year. The upper $95 \%$ confidence limit for the cardiovascular event threshold at which benefit equals harm was $0.8 \%$ /year; this cardiovascular event risk is equivalent to a coronary heart disease event risk of $0.6 \% /$ year. ${ }^{15}$ This analysis was repeated excluding the data 


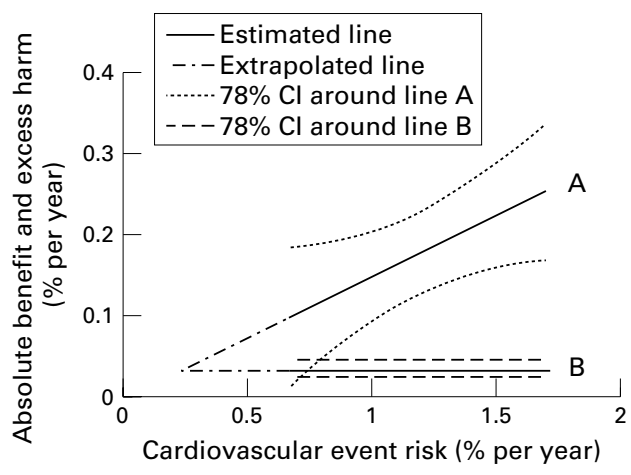

Figure 1 Absolute benefit (reduction in all cardiovascular events) (line A) and absolute harm (increase in major bleeds) (line B) from aspirin treatment, related to absolute cardiovascular event risk. The dotted lines show the $78 \%$ confidence regions. By extrapolation, benefit and harm from aspirin are equal when cardiovascular event risk is

$0.22 \% / y e a r$, with an upper $95 \%$ confidence limit for this estimate at a cardiovascular event risk of approximately $0.8 \% /$ year

from the UK doctors study, which was the source of significant heterogeneity. This made no important difference to the point at which benefit equalled harm for aspirin treatment, which was a cardiovascular event risk of $0.21 \% /$ year.

NET BENEFIT AND NNT FOR ASPIRIN RELATED TO CORONARY HEART DISEASE EVENT RISK

Table 4 sets out benefit (number of myocardial infarctions prevented and NNT) net of bleeding complications of different severity, assuming that 100 people are treated for five years, for coronary heart disease event risks of $0.5 \%$, $1.0 \%$, and $1.5 \%$ a year. At a coronary heart disease event risk of $0.5 \% / y e a r$, the NNT to prevent a myocardial infarction is 133 , and the NNT to prevent myocardial infarction without cerebral haemorrhage or a major bleed causing death, transfusion, or operation is 256. If all non-minor bleeding complications are considered, there is net harm from aspirin treatment at that coronary heart disease risk, with a number needed to harm (NNTH) of 500. At a coronary heart disease event risk of $1.5 \%$ /year the NNT to prevent a myocardial infarction is 44 , and to prevent a myocardial infarction without cerebral or major haemorrhage, 53. If all nonminor bleeding complications are included there is still benefit, with a NNT net of any complication of 77 (69 to 88). At the intermediate coronary heart disease risk level, $1.0 \%$ / year, there is net benefit from aspirin treatment even if all non-minor bleeds are considered (table 4). However, benefit is relatively small, with the NNT to prevent myocardial infarction 67 , and to prevent myocardial infarction without cerebral or major haemorrhage, 88 .

\section{Discussion}

There were difficulties in performing this meta-analysis. End points for benefit were reasonably uniform among the trials, but the analysis for myocardial infarction had to be forced through despite significant heterogeneity. This is a concern because prevention of myocardial infarction was entirely responsible for the significant reduction in all cardiovascular events. Significant heterogeneity could result from differences in study design, aspirin dose, type of people studied, compliance, or other factors (table 1), but the reason is not obvious. It may be a chance observation. Diagnosis of cerebral haemorrhage was incomplete in some trials - hence the decision to embed these complications within strokes rather than strip them out. This method of analysis is accurate numerically when defining the relation between benefit and harm, but may not be accurate quantitatively if cerebral haemorrhages are more severe than non-haemorrhagic strokes. There was some evidence for this in the UK doctors study, as strokes on aspirin were more often disabling than those in the control group. ${ }^{10}$ Reporting of bleeding complications in the four trials was extremely diverse. ${ }^{11}$ However, odds ratios for bleeding complications were similar whichever end point was used, and the overall odds ratio (1.69) was close to that for cerebral haemorrhage (1.84) reported in another meta-analysis. $^{2}$

The estimate of relative risk for bleeds is probably reliable. There is much less certainty for the absolute risk of bleeding complications in the control groups. For each of the categories, major bleeds and all non-minor bleeds, only two trials could be used, and the absolute risk of all non-minor bleeds in control groups differed substantially, presumably because of differences in classification. The combined estimate for all non-minor bleeds must therefore be regarded with caution. It was retained because it provides the most conservative estimate of balance between benefit and harm, and also describes the outcome with aspirin $75 \mathrm{mg}$ daily, ${ }^{56}$ the dose now widely used. Our conclusions rely on assumptions that the relative risk reduction with aspirin is constant, so that benefit is linearly related to absolute risk, ${ }^{13}$ whereas the absolute risk of bleeding is constant and independent of coronary or cardiovascular risk. ${ }^{2}{ }^{3}$ These

Table 4 Absolute reduction in myocardial infarctions by aspirin treatment of 100 persons for five years, and NNT, assuming relative risk reduction of $30 \%$; and benefit net of bleeding complications of different severity

\begin{tabular}{|c|c|c|c|c|c|c|}
\hline \multirow[b]{2}{*}{ Myocardial infarcts prevented } & \multicolumn{6}{|c|}{ CHD event risk } \\
\hline & $\begin{array}{l}0.5 \% / \text { year } \\
M I \text { prev }\end{array}$ & NNT & $\begin{array}{l}1.0 \% / \text { year } \\
\text { MI prev }\end{array}$ & NNT & $\begin{array}{l}1.5 \% / \text { year } \\
\text { MI prev }\end{array}$ & NNT \\
\hline Total & 0.75 & 133 & 1.50 & 67 & 2.25 & 44 \\
\hline Net of cerebral haemorrhage $(0.19)^{\star}$ & 0.56 & 179 & 1.31 & 76 & 2.06 & 49 \\
\hline Net of major bleeds $(0.17)^{\star}$ & 0.39 & 256 & 1.14 & 88 & 1.89 & 53 \\
\hline Net of non-minor bleeds $(0.76)^{\star}$ & -0.20 & $(500) \dagger$ & 0.55 & 182 & 1.30 & 77 \\
\hline
\end{tabular}

*Absolute risk of bleeding complications in 100 persons per five years, assumed constant and independent of CHD event risk.

$\nmid$ Number treated for five years to harm one person (NNTH).

MI prev, myocardial infarcts prevented; NNT, number needed to treat for five years. 
Sheffield Table for Primary Prevention of Cardiovascular Disease

Shawing serum total:HOL cholesterol ratios conferring estimated risks of CHO events of $15 \%$ and $30 \%$ over 10 years.

\begin{tabular}{|c|c|c|c|c|c|c|c|c|c|c|c|c|c|c|c|c|}
\hline \multirow{5}{*}{$\begin{array}{l}\text { Men: } \\
\text { Hhpertenaion } \\
\text { Smaking } \\
\text { Diabutes } \\
\text { CHD risk }\end{array}$} & \multicolumn{16}{|c|}{ Total : HDL cholesterol ratio } \\
\hline & \multirow{3}{*}{\multicolumn{2}{|c|}{$\begin{array}{l}\text { Yes } \\
\text { Yes } \\
\text { Yos }\end{array}$}} & \multirow{3}{*}{\multicolumn{2}{|c|}{$\begin{array}{l}\text { Ne } \\
\text { Yes } \\
\text { Yes }\end{array}$}} & \multirow{3}{*}{\multicolumn{2}{|c|}{$\begin{array}{l}\text { Yes } \\
\text { Yes } \\
\text { No }\end{array}$}} & \multirow{2}{*}{\multicolumn{2}{|c|}{$\begin{array}{l}\text { Yes } \\
\text { No } \\
Y=s\end{array}$}} & \multirow{2}{*}{\multicolumn{2}{|c|}{$\begin{array}{l}\text { No } \\
\text { Yes }\end{array}$}} & \multirow{2}{*}{\multicolumn{2}{|c|}{$\begin{array}{l}\text { No } \\
\text { No }\end{array}$}} & \multicolumn{2}{|c|}{ Yes } & \multicolumn{2}{|c|}{ No } \\
\hline & & & & & & & & & & & & & & & & \\
\hline & & & & & No & & \multicolumn{2}{|c|}{ Yes } & \multicolumn{2}{|c|}{ Na } & \multicolumn{2}{|c|}{ Yes } & \multicolumn{2}{|c|}{ No } & \multicolumn{2}{|c|}{ No } \\
\hline & $15 \%$ & $30 \%$ & $15 \%$ & $30 \%$ & $15 \%$ & 3023 & $15 \%$ & $30 \%$ & $15 \%$ & $30 \%$ & $15 \%$ & $30 \%$ & $15 \%$ & $30 \%$ & $15 \%$ & $30 \%$ \\
\hline$A 00 \quad 70$ & 2.0 & 30 & 20 & गक & 21 & 38 & 24 & 4.4 & 2.5 & 48 & 2.9 & 51 & 3.1 & 6.6 & 3.7 & 0.7 \\
\hline eฮ & 2.0 & 32 & 2.1 & 3i & 22 & 43 & 26 & 4. & 2.7 & $4 \mathrm{a}$ & 3.0 & 126 & 3.3 & 5.1. & 39 & 71 \\
\hline 56 & 2.0 & 34. & 2.2 & 40 & 24 & 43 & 27 & 5.0 & 2.3 & 52 & 3.2 & 5.0 & 3.6 & $\theta 9$ & 41 & 70 \\
\hline 64 & 20 & 36 & 2.4 & 4.3 & 28 & $4 a$ & 29 & d.1. & 3.0 & 38 & 3.5 & 33 & 3.7 & 6. & 4.4 & H \\
\hline 62 & 2.1 & 3.: & 2.5 & 45 & 27 & 49 & 3.1 & 56 & 3.2 & 5.8 & 3.7 & 87 & 3.9 & 72 & 47 & स्वे \\
\hline tei & 22 & 4.9 & 2.7 & 49 & 29 & 52 & 33 & E. 5 & 3.4 & 63: & 3.9 & 72 & 4.2 & 77 & 50 & 92 \\
\hline 58 & 24 & it & 2.9 & 5.3 & 31 & ss & 35 & 0.5 & 37 & Q2. & 4.2 & 78 & 4.5 & a.s & 8.4 & $7 \geqslant$ \\
\hline 56 & 26 & 4.7 & 3.1 & 57 & 3.3 & ab & 3.8 & 70 & 40 & 72 & 4.6 & 83 & 4.9 & 85 & 5.8 & $10 \mathrm{a}$ \\
\hline 54 & 28 & 51 & 3.3 & a. 1 & 3.6 & 5.5 & 4.1 & 75 & 43 & 78 & 4.9 & 90 & 5.2 & 98 & 6.3 & $=$ \\
\hline 52 & 30 & 58 & 3.6 & 56 & 3.9 & 70 & 4.4 & a. 1 & 46 & di. & 5.3 & 97 & 0.7 & 104 & 6.8 & . \\
\hline 50 & 33 & t1.0 & 3.9 & 71 & 4.2 & to & 4.8 & 100 & 8.0 & 91 . & 5.7 & 105 & 6.1 & 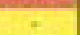 & 7.3 & . \\
\hline 48 & 3.6 & 6.9 & 4.3 & 78 & 4.5 & $B 3$ & 5.2 & i. $\bar{a}$ & 5.4 & 39 & 6.3 & - & 6.7 & - & 8.0 & - \\
\hline 46 & 39 & 71 & 48 & 85 & 5.0 & 91 & 57 & 104 & 59 & to. & 6.8 & , & 7.3 & . & 8. 7 & , \\
\hline 44 & 4.3 & 7.:. & 5.1 & 21 & 5.4 & 99 & 6.3 &. & 6.5 & 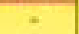 & 75 & . & 8.0 & - & 9.6 & . \\
\hline 42 & 4.7 & as & 5.6 & 102 & 6.0 & 109 & 6.9 & - & 72 & - & 82 & - & 8.8 & + & 10.5 & - \\
\hline 40 & $B 2$ & 9.3 & 6.2 & . & 6.6 & $\cdot$ & 7.6 & - & 7,9 & - & 2.1 & - & 9.7 & - & & \\
\hline 38 & 58 & 10.5 & 6.9 & - & 7.3 & - & 8.5 & - & 8.8 & . & 10.1 & - & 10.8 & . & & \\
\hline 36 & 6.4 & $r$ & 77 & . & 8.2 &. & 9.5 & . & 9.8 & 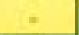 & & & & & & \\
\hline 34 & 7.2 & . & 5.6 & . & 9.2 & . & 10.6 & + & & & & & & & & \\
\hline 32 & 8.2 & . & 9.3 & - & 10.5 & - & & & & & & & & & & \\
\hline 30 & 6.4 & $=$ & & & & & & & & & & & & & & \\
\hline 28 & 10.8 & - & & & & & & & & & & & & & & \\
\hline
\end{tabular}

\begin{tabular}{|c|c|c|c|c|c|c|c|c|c|c|c|c|c|c|c|c|}
\hline \multirow{4}{*}{$\begin{array}{l}\text { Women: } \\
\text { Hipertension } \\
\text { Smaking } \\
\text { Diatuntes } \\
\end{array}$} & \multicolumn{16}{|c|}{ Total : HOL cholesterol ratio } \\
\hline & \multicolumn{2}{|c|}{ Yes } & \multicolumn{2}{|c|}{ No } & \multicolumn{2}{|c|}{ Yes } & \multicolumn{2}{|c|}{ Yes } & \multicolumn{2}{|c|}{ No } & \multicolumn{2}{|c|}{ No } & \multicolumn{2}{|c|}{ Yes } & \multicolumn{2}{|c|}{ No } \\
\hline & \multirow{2}{*}{\multicolumn{2}{|c|}{$\begin{array}{l}\text { Yos } \\
\text { Yes } \\
\end{array}$}} & \multirow{2}{*}{\multicolumn{2}{|c|}{$\begin{array}{r}\text { Yes } \\
\text { Yos } \\
\end{array}$}} & & & \multirow{2}{*}{\multicolumn{2}{|c|}{$\begin{array}{l}Y e a \\
\mathrm{Na}\end{array}$}} & \multirow{2}{*}{\multicolumn{2}{|c|}{$\begin{array}{l}\text { Na } \\
\text { Yes }\end{array}$}} & & & \multirow{2}{*}{\multicolumn{2}{|c|}{ No }} & \multirow{2}{*}{\multicolumn{2}{|c|}{ No }} \\
\hline & & & & & & & & & & & & & & & & \\
\hline CHD risk & $15 \%$ & $30 \%$ & $15 \%$ & $30 \%$ & $15 \%$ & $30 \%$ & $15 \%$ & $30 \%$ & $15 \%$ & $30 \%$ & $15 \%$ & $30 \%$ & $15 \%$ & $30 \%$ & $15 \%$ & $30 \%$ \\
\hline Age $\quad \pi$ & 2.3 & 4.1 & 27 & 40 & 33 & 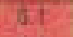 & 3.8 & 70 & 4.0 & 72 & 4.6 & 9.3 & 5.6 & 102 & 6.7 & - \\
\hline 68. & 2.3 & +2 & 2.7 & $5 \cdot 0^{2}$ & 34 & at. & 39 & 78 & 40 & 73 & 4.6 & 84 & 5.7 & - & 88 & - \\
\hline 66 & 2.3 & 42 & 28 & 8.1 & 34 & 84 & 39 & 79 & 4.1 & +4 & 4.7 & 35 & 6.7 & . & 69 & . \\
\hline 84 & 2.4 & 13 & 2.8 & 92 & 35 & E. 4 & 40 & 7.3 & 4.2 & 7,5 & 4. $\mathrm{B}$ & 77 & 5.9 & - & 70 & - \\
\hline 62 & 2.4 & 44 & 2.9 & 53 & 36 & As & 4.1 & 75 & 43 & $7 a$ & 4.8 & 90 & 6.0 & . & 72 & + \\
\hline Et & 2.5 & 46 & 30 & 55 & 37 & 57 & 42 & 7,7 & 44 & a) & 5.1 & 83 & 6.2 & - & 7.4 & - \\
\hline 58 & 28 & 43 & 3.1 & 97 & 38 & $7 \mathrm{aI}$ & 4.4 & a.t. & 4.6 & 84 & 5.3 & 96 & 6. 5 & . & 7.8 & * \\
\hline 50 & 2.7 & 80 & 3.3 & In & 40 & 74 & 46 & B. 4 & 48 & $8 \mathrm{a}$ & 5.5 & 191 & 6.8 & - & 8.1 & - \\
\hline 54 & 2.8 & $5 x$ & 35 & 8,3 & 4.3 & 70 & 49 & 0.0 & 5.1 & 93 & 5.8 & $=$ & 7.2 & - & 8.6 & $*$ \\
\hline 52 & 3.1 & 36 & 3.7 & aid & 4.6 & a.J & 52 & 9.1 & 5.4 & 94 & 6.2 & . & 7.7 & . & 92 & - \\
\hline 51 & 3.3 & 61 & 4.0 & 7,3 & 4.9 & 30 & 5.6 &. & 5.9 & , & 6.7 & . & 6. 3 & . & 9.9 & + \\
\hline 48 & 3.6 & 65 & 4.3 & 79 & 5.3 & 38 & 6.1 & + & 6.4 & - & 7.3 & - & 9.0 & - & & \\
\hline 46 & 40 & 73 & 4.8 & a:5 & 5.9 & - & 6.8 & - & 7.1 & + & 8.1 & , & 10.0 & $\cdot$ & & \\
\hline 44 & 4.5 & ad & 5.4 & 91 & 6.6 & r & 78 & * & 7.9 & * & 9.1 & $=$ & & & & \\
\hline 42 & 5.1 & 94 & 6.1 & + & 7.5 & - & 8.6 & - & 90 & - & 10.3 & - & & & & \\
\hline 4 & 5.9 & * & 7.1 & . & a. 7 & $*$ & 10.0 &. & & & & & & & & \\
\hline 38 & 70 & - & B.4 & - & & & & & & & & & & & & \\
\hline 36 & 85 & + & 10.2 & - & & & & & & & & & & & & \\
\hline
\end{tabular}

Read before using table

- Do not use for secondary prevention: patients with MI, angina, PVD, non-hoemerrhagic stroke, TM, ar diabetes with microvascular complications have high $\mathrm{CHO}$ risk. Treat meld hypertension: treat with espirin and treat with stetin if serum cholesterol $\geq 5.0 \mathrm{mmol}$.

- Treat hypertension above mild range (average $\geq 160$ or $\geq 100$ )

- Treat mild hypertension (140-159 or $90-99)$ with target organ damage (LVH, proteinuria, renal impaiment) or with diabetes (type 1 or Z)

- Consider drug treatment only after 6 monthe of eppropriale advice on smoking, det and repeated BP measuraments

- Use average of repeated total: $\mathrm{HDL}-\mathrm{C}$ measurements. if $\mathrm{HDL}-\mathrm{C}$ not available, assume $1.2 \mathrm{mmol}$

- Those with sotal:HDL-C ratio $>8.0$ may have tamilial hyperlipidaemia

- The table underestimates CHD risk in

$$
\begin{aligned}
& \text { - LVH on ECG (risk doubled - add } 20 \text { years } 10 \text { age) } \\
& \text { - family history of premature CHD (add } 6 \text { years) } \\
& \text { - familial hyperipidoomia } \\
& \text { - British Asians }
\end{aligned}
$$

Wallis EJ, Ramsay LE et al. BMJ 2000,320:671-676. woww.bmicom

Figure 2 Sheffield table for primary prevention of cardiovascular diseases
Instructions

- Chocese tabia for men or women

- Hypertension masns SBP $\geq 140$ or DBP $\geq 90$ or on antimpertensive treatment

- Identify correct column for hypartension, smoking and disbeles

- Identify row showing age

- Read off fotal:HOL-C ratios at intersection of column and row. If there is an entry, measure serum choiesterol:HDL ratio.

- If no entry. lipids need not be massured unlass famlial hyperfpidoemia suspocted

- If total:HDL-C ratio confers CHD risk of $15 \%$, consider trestment of mild bypertension (SBP 140-159 or DEP 90-59) and with aspirin

- Ir sotalHDL-C ratio confers CHD risk of $30 \%$, consider statin if serum chclesterol $\geq 5.0$ mmoll

- Decisions on statin at CHD risk between $15 \%-30 \%$ depend on local policy

- The table cen be used to assess CHD risk at an oider age 
assumptions are valid as far as they have been tested, ${ }^{1-3}$ but the data are insufficient to test them rigorously.

A subgroup analysis of the thrombosis prevention trial published recently ${ }^{16}$ showed significant differences in benefit from aspirin according to systolic blood pressure, age, and serum cholesterol, findings that might cast doubt on the constancy of relative risk reduction by aspirin. However, these findings were not consistent in subgroup analyses of the US physicians study ${ }^{4}$ and the HOT study, ${ }^{17}$ and indeed in some instances are entirely inconsistent. ${ }^{18}$ There is a need to examine the relation of aspirin benefit to pretreatment coronary heart disease risk in greater depth, perhaps using the data for individual participants from all available trials. ${ }^{19}$ Finally, those studied are not representative of the whole population. Relatively few women were included, and the findings apply only to hypertension that is well controlled. ${ }^{5}$

Given these difficulties why perform the analysis at all? These trials have shown substantial reductions in non-fatal myocardial infarction, ${ }^{4-6}{ }^{19}$ and this has to be translated to ordinary practice. Advice that aspirin may be prescribed for primary prevention to those at high coronary risk $^{37}$ is of little value unless "high coronary risk" is defined. Furthermore $6-9 \%$ of the population take aspirin regularly, ${ }^{89}$ and those with low coronary risk may come to serious harm. Given the difficulties discussed above, conclusions should err on the conservative side. We have tended to underestimate benefit by excluding end points such as prevention of transient ischaemic attacks or angina, ${ }^{10}$ which are important. We have probably overweighted harm. We suspect that most people would prefer a myocardial infarct to a cerebral haemorrhage, but most would choose a non-cerebral haemorrhage needing transfusion over a myocardial infarct. By according major haemorrhages and major cardiovascular events equal weight in the analysis of safety we probably understate the value of preventing cardiovascular events. In the analysis of safety we used the upper $95 \%$ confidence limit to define the level of coronary heart disease risk at which it is reasonably certain that harm from aspirin will not exceed benefit.

Aspirin for primary prevention is more likely to do good than harm provided the cardiovascular event risk is $\geqslant 0.8 \% /$ year, equivalent to a coronary heart disease event risk $\geqslant 0.6 \% /$ year. ${ }^{15}$ Table 4 shows that aspirin at a coronary heart disease event risk of $0.5 \%$ year is unattractive. The five year NNT to prevent a myocardial infarction is high (133), and the NNT for benefit without a major haemorrhagic complication is 256 . Numerically the risk of major plus all non-minor bleeding outweighs benefit. Aspirin treatment at this coronary heart disease risk level is not justified. At a coronary heart disease event risk of $1.5 \%$ /year (table 4) the outcome appears acceptable, with a five year NNT of 44 to prevent a myocardial infarct, and of 53 to prevent a myocardial infarct without a cerebral or major haemorrhage. Benefit exceeds harm even if all non-minor bleeds are included. At an interme- diate coronary heart disease event risk level, $1 \% /$ year, benefit is relatively small (table 4 ). We suggest that people with coronary heart disease event risk of $1.5 \%$ /year or higher with no contraindication to aspirin should be identified for treatment. Individuals with low coronary heart disease risk, below $1.0 \% / y e a r$, should not be treated.

Aspirin cannot be prescribed safely for primary prevention of coronary heart disease without formal estimation of coronary disease event risk of the individual. Intuitive assessment of coronary heart disease risk $^{20}$ and reliance on single risk factors such as lipids or blood pressure ${ }^{2122}$ are highly inaccurate. Simple counting of coronary heart disease risk factors improves accuracy, ${ }^{22}$ but still identifies people at very low risk and fails to identify all high risk people for treatment. ${ }^{23}$ Accurate risk estimation requires counting and weighting of major risk factors for coronary heart disease, ${ }^{22}$ using risk functions derived from epidemiological studies such as Framingham. ${ }^{21}$ Aspirin treatment for primary prevention should be guided by formal estimation of coronary heart disease risk using the full Framingham equation, ${ }^{21}$ or simple methods based on Framingham. ${ }^{15}{ }^{24}$ This is recommended in recent joint British societies' guidelines for coronary heart disease prevention ${ }^{24}$ and British Hypertension Society guidelines. ${ }^{25}$ In these guidelines the risk threshold for aspirin use for primary prevention is set at coronary heart disease event risk $\geqslant 15 \%$ over 10 years, which is identical to the $1.5 \% /$ year coronary disease risk threshold identified in the present analysis. We have revised the Sheffield table ${ }^{15}$ to implement these guidelines, and to show the coronary heart disease risk threshold (15\% over 10 years, equivalent to $1.5 \%$ /year) at which aspirin treatment is indicated (fig 2). This table has a sensitivity of $97 \%$ for detecting a coronary heart disease event risk of $\geqslant 15 \%$ over 10 years, and will not identify for aspirin treatment any individual with a calculated coronary disease event risk below $10 \%$ over 10 years. ${ }^{15}$

1 Antiplatelet Trialists' Collaboration. Collaborative overview of randomised trials of antiplatelet therapy. I. Prevention of death, myocardial infarction and stroke by prolonged antiplatelet therapy in various categories of patients. $B M \mathcal{F}$ 1994;308:81-106.

$2 \mathrm{He}$ J, Whelton PK, Vu B, et al. Aspirin and risk of haemorrhagic stroke. A meta analysis of randomized controlled trials. fAMA 1998;280:1930-35.

3 Boissel J. Individualizing aspirin therapy for prevention of cardiovascular events. $\mathscr{f} A M A$ 1998;280:1949-50.

4 The Steering Committee of the Physicians' Health Study Research Group. Final report on the aspirin component of Research Group. Final report on the aspirin component of
the ongoing Physicians' Health Study. N Engl F Med 1989; the ongoing Phy

5 The Medical Research Council's General Practice Research Framework. Thrombosis prevention trial: randomised trial of low intensity oral anticoagulation with warfarin and lowdose aspirin in the primary prevention of ischaemic heart disease in men at increased risk. Lancet 1998;351:233-41.

6 Hansson L, Zanchetti A, Curruthers SG, et al. Effects of intensive blood-pressure lowering and low dose aspirin in patients with hypertension: principal results of the Hypertension Optimal Treatment (HOT) randomised trial. Lancet 1998;351:1755-62.

7 Hennekens CH, Dyken ML, Fuster V. Aspirin as a therapeutic agent in cardiovascular disease. A statement for healthcare professionals from the American Heart Association. Circulation 1997;96:2751-53.

8 Weil J, Colin-Jones D, Langman M, et al. Prophylactic aspiWeil J, Colin-Jones D, Langman M, et al. Prophylactic aspi-
rin and the risk of peptic ulcer bleeding. BMF 1995;310: rin and $827-30$.

9 Kelly JP, Kaufman DW, Juregelon JM, et al. Risk of aspirin associated major upper gastrointestinal bleeding with enteri coated or buffered product. Lancet 1996;348:1413-16. 
10 Peto R, Gray R, Collins R, et al. Randomised trial of prophylactic daily aspirin in British male doctors. BMF

11 Isles C, Norrie J, Paterson J, et al. Risk of major gastrointestinal bleeding with aspirin. Lancet 1999;353:148. 12 Armitage P, Berry G. Statistical methods in medical research, 3rd ed. Oxford: Blackwell, 1994:215-19, 169-71.

13 Lubsen J, Tijssen JGP. Large trials with simple protocols: indications and contraindications. Control Clin Trials 1989; 10:151-60S.

14 Altman DG. Confidence intervals for number needed to treat. BMF 1998;317:1309-12.

15 Wallis EJ, Ramsay LE, Haq IU, et al. Coronary and cardiovascular risk estimation for primary prevention: population validation of a new Sheffield table. BMF 2000;320:671-6. 16 Meade TW, Brennan PJ, on behalf of the MRC General Practice Research Framework. Determination of who may derive most benefit from aspirin in primary prevention 2000;321:13-17.

Kjeldsen SE, Kolloch RE, Leonetti G, et al, for the HOT Study Group. Influence of gender and age on preventing cardiovascular disease by antihypertensive treatment and acetylsalicylic acid. The HOT Study. $\mathcal{F}$ Hypertens 2000;18 629-42.
18 Ramsay LE, Sanmuganathan PS, Wallis EJ, et al. Aspirin for primary prevention. http://www.bmj.com/cgi/eletters/321/ 7252/13\#EL4

19 Baigent C, Murphy M, Foster C, et al. Primary prevention. Clinical Evidence 2000;3:65-6, 74-5.

20 Grover SA, Lowensteyn I, Esrey KL, et al. Do doctors accurately assess coronary risk in their patients? Preliminary results of the coronary health assessment study. BMF 1995; 310:975-8.

21 Anderson KM, Odell PM, Wilson PWF, et al. Cardiovascular risk profiles. Am Heart f 1991;121:293-8.

22 Grover SA, Coupal L, Hu X. Identifying adults at increased risk of coronary disease. How well do the current cholesterol guidelines work? $\mathscr{f} A M A$ 1995;274:801-6.

23 Haq IU, Ramsay LE, Jackson PR, et al. Prediction of coronary risk for primary prevention of coronary heart disease: a comparison of methods. $Q \mathcal{F}$ Med 1999;92:379-85.

24 Wood D, Durrington P, Poulter N, et al. Joint British recommendations on prevention of coronary heart disease in clinical practice. Heart 1998;80:S1-29.

25 Ramsay LE, Williams B, Johnston GD, et al. British Hypertension Society guidelines for hypertension management 1999: summary. BMf 1999; 319:630-5

\section{IMAGES IN CARDIOLOGY}

\section{Intra-left atrial invasive mass extended via the pulmonary vein}

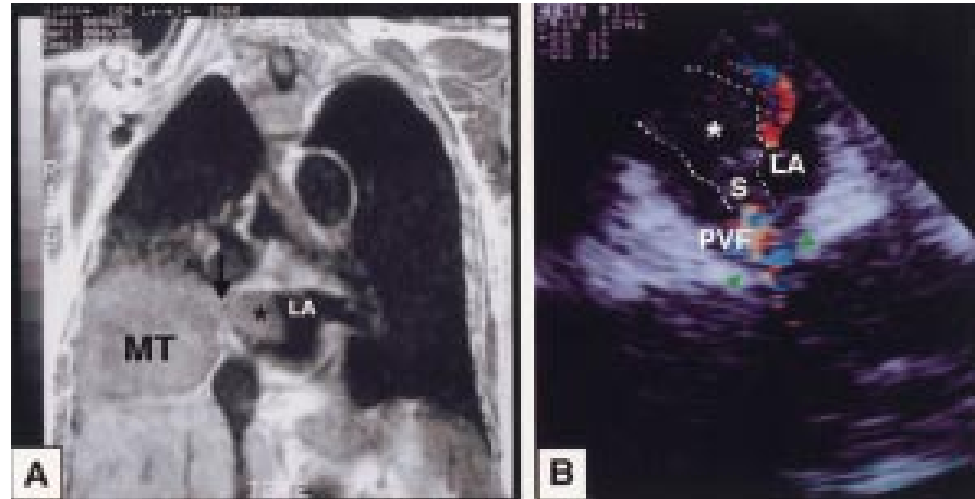

Figure 1 (A) MRI shows that the main tumour (MT) in the right middle lobe seems to extend directly into the left atrium ( $L A$ ) through the right pulmonary vein via a stalk-like projection (arrow) and to make an intra-atrial abnormal invasive mass (*). (B) TOE shows the mass $\left(^{\star}\right)$ in the LA measures about $2.5 \mathrm{~cm}$ in diameter. Colour Doppler imaging reveals the mass to have a stalk $(S)$ derived from the right pulmonary vein (arrowhead) which appears to provide its blood flow (PVF). The broken line outlines the edge of the invasive mass
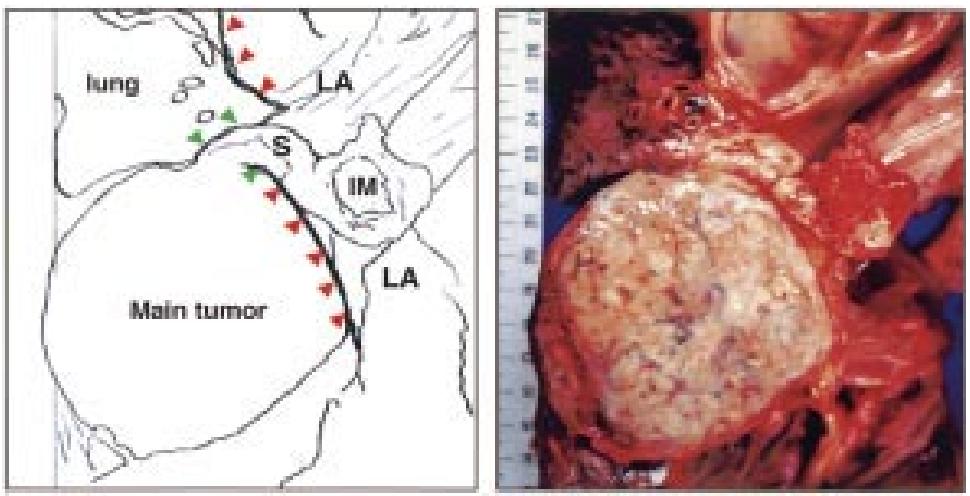

Figure 2 Necropsy findings. The primary tumour in the lung (main tumour) directly extends into the right middle pulmonary vein (green arrowheads) to form a tumour stalk (S) through the vein as well as the invasive mass (IM) in the left atrium (LA). The primary tumour does not directly invade through the LA wall, which forms a clear border (red arrowheads) between the main tumour and the LA lumen.
A 78 year old man was admitted complaining of cough and sputum. Percutaneous needle biopsy identified a right middle lobe mass as squamous cell carcinoma of the lung. Magnetic resonance imaging (MRI) seemed to show that the tumour in the right middle lobe extended continuously into the left atrium via the right pulmonary vein. Transoesophageal echocardiography (TOE) showed that the atrial mass was polyp-like in shape (about $2.5 \mathrm{~cm}$ in diameter) with a centralised low echo area, an irregular surface, and a stalk derived from the area of the right pulmonary vein. Colour Doppler showed blood flow from the pulmonary vein into the left atrium around the stalk of the mass. The patient died 10 months after the first symptoms arose. The necropsy findings were compatible with the clinical image data of MRI and TOE. There were no direct attachments between the atrial mass and the left atrial wall other than the stalk.

Few reports of primary lung cancer with intra-left atrial extension via the pulmonary vein have been previously documented. $\mathrm{Pa}-$ tients with intracardiac metastases are exposed to the risk of tumour embolisation during operation on the lung or at spontaneous attack. Fortunately, there was no massive tumour embolism in our case. In cases of malignant tumour suggesting cardiac invasion, TOE should be performed to elucidate the mode of invasion of the tumour. This information may not only prove valuable in predicting the prognoses, but may also be essential in deciding the method of treatment and follow-up observations of these patients.

NOBORU WATANABE
KEISHI KUBO
wwata@hsp.md.shinshu-u.ac.jp

